Ciência e Natura, Santa Maria, v. 37 n.4 set-dez. 2015, p. 651-663

Revista do Centro de Ciências Naturais e Exatas - UFSM

ISSN impressa: 0100-8307 ISSN on-line: 2179-460X

\title{
Análise da qualidade da água de poços artesianos do município de Imigrante, Vale do Taquari/RS
}

\author{
Analysis of water quality of the Imigrante Municipality in the Taquari Valley/RS \\ Cristian Mateus Zerwes ${ }^{1}$, Mariela Inês Secchi², Thanabi Bellenzier Calderan², \\ Jaqueline de Bortoli ${ }^{1}$, Jaqueline Fernandes Tonetto ${ }^{1}$, Maicon Toldi ${ }^{1}$, \\ Eniz Conceição de Oliveira ${ }^{3}$, Eduardo Rodrigo Ramos de Santana ${ }^{3}$
}

\author{
${ }^{1}$ Mestrandos do Programa de Pós-Graduação em Ambiente e Desenvolvimento - PPGAD, Centro \\ Universitário UNIVATES, Lajeado/RS \\ ${ }^{2}$ Doutorandas do Programa de Pós-Graduação em Ambiente e Desenvolvimento - PPGAD, Centro \\ Universitário UNIVATES, Lajeado/RS \\ ${ }^{3}$ Professores titulares do Programa de Pós-Graduação em Ambiente e Desenvolvimento - PPGAD, Centro \\ Universitário UNIVATES, Lajeado/RS
}

\section{Resumo}

Um dos maiores desafios enfrentados pelas presentes e futuras gerações é encontrar formas de preservação das fontes de água, livres de contaminações e adequadas ao consumo da população. Essa dificuldade está relacionada à contaminação dos lençóis freáticos devido à ocupação e uso do solo pela sociedade, alterando os processos físicos, químicos e biológicos dos sistemas naturais, causando inúmeras doenças e muitas vezes levando a morte. O presente trabalho objetivou avaliar a qualidade da água das principais fontes naturais do município de Imigrante, localizado no Vale do Taquari-RS a fim de averiguar a potabilidade das águas consumidas pelas comunidades do município. Na presente pesquisa foram selecionados dez poços para a verificação das características físico-químicas e biológicas, tais como: $\mathrm{pH}$, condutividade, sólidos suspensos, turbidez, oxigênio dissolvido, carbono orgânico, carbono total, carbono inorgânico, nitrogênio, dureza média, temperatura, condutividade e análise microbiológica, comparando os resultados com os padrões preestabelecidos pela legislação vigente. Dos dez poços analisados, seis apresentaram-se fora dos parâmetros estabelecidos pela legislação. Este é o caso dos níveis de turbidez, colorimetria, sólidos totais, nitrato, Coliformes totais e Escherichia coli, parâmetros que em excesso tornam imprópria a água para o consumo com efeitos sobre sua palatabilidade, conferindo propriedades laxantes e mesmo, indiretamente, indicar a presença de patógenos que podem ter graves repercussões sobre a saúde. Assim, este estudo destaca a necessidade de utilizar os métodos de desinfecção de água de poços antes de seu consumo.

Palavras-chave: Água. Análise. Avaliação físico-química e biológica. Legislação Ambiental.

Abstract

One of biggest challenges faced by present and future generations is to find ways to preserve water sources without contamination and suitable for consumption by population. This difficulty is related to contamination of groundwater sources, due to the occupation and use of land by society, altering the physical, chemical and biological processes of natural systems, causing many diseases and often leading to death. This study aimed to evaluate the water quality of the main natural sources from the municipality of Imigrante, located in the political region of Taquari Valley, Rio Grande do Sul state, Brazil, to ascertain the potability of the water consumed by the communities in the city. In this research were selected ten wells, for verification of physical, chemical and biological characteristics, such as: $\mathrm{pH}$, conductivity, suspended solids, turbidity, dissolved oxygen, organic carbon, total carbon, inorganic carbon, nitrogen, medium hardness, temperature, conductivity and microbiological analysis, comparing the results with the standards previously established by current legislation. Among the ten wells analyzed, six presented parameters with values were above the threshold established by law. This is the case for turbidity, colorimetry, total solids, nitrates, total coliforms and Escherichia coli. These parameters, in excess, make water inadequate for consumption with effect on its palatability, giving it laxative properties and even indirectly indicate the presence of pathogens that can cause serious repercussions on health. Thus, this study highlights the need to apply disinfection methods on the well water prior its consumption.

Keywords: Water. Analysis. Physical, chemical and biological evaluation. Environmental legislation. 


\section{Introdução}

A água é um recurso natural essencial à sobrevivência dos seres vivos na terra. Isso em razão de se constituir um componente bioquímico indispensável para a totalidade dos seres vivos, incluindo-se nessa percepção a raça humana. A água é o ambiente indispensável para inúmeras espécies animais e vegetais. Organismos podem sobreviver sem ar, porém, nenhum deles consegue sobreviver sem água (RUTKOWSKI; LESSA e OLIVEIRA, 1999, p. 05).

Cerca de $75 \%$ da composição corporal dos seres humanos é composta por água; nos vegetais, pode representar até $90 \%$ da composição e a sua falta nos pode levar a deterioração de ecossistemas.

Embora mais de $70 \%$ do planeta seja constituído de água, somente cerca de 3\% desta se encontra disponível para o consumo humano. Além disso, com a explosão industrial, urbana, agrícola e o avanço das ciências médicas houve contribuição para o aumento populacional, que passaram a consumir mais água, tornando-a mais escassa (BARROS e AMIM, 2008).

Sabe-se que do volume total da água do planeta, a presença de água salgada, nos oceanos e mares, corresponde a $97,5 \%$ e a de água doce, em rios, lagos, geleiras e subsolo, corresponde apenas $2,5 \%$. Desta pequena quantidade de água doce, $68,9 \%$ encontra-se em geleiras e coberturas permanentes de neve, $29,9 \%$ é relacionado à água doce subterrânea e 0,3\% são das águas dos rios e lagos (ALMEIDA, 2010).

Bertoldi (2001) explica que a escassez de água potável, sua distribuição, acesso e gestão foram, são e serão, motivos de grandes disputas internas e internacionais. A água potável, componente básico da biosfera, se encontra em um movimento de diminuição tão acelerado que a previsão para 2050 é de que 2,5 bilhões de pessoas não terão acesso ao precioso líquido vital. Hoje, este número é de cerca de 1 bilhão de pessoas.

Segundo a Organização das Nações Unidas para a Alimentação e Agricultura - FAO e o Banco Mundial, no ano de 1990, 20 países nove no Oriente Médio e onze na África - sofriam pela falta de água. Em 1996 já eram 26 e em 2020 serão 41. Apenas 2,5\% da água existente em nosso planeta é doce, provavelmente em contagem decrescente. Segundo Bertoldi (2001) a escassez dá-se principalmente pela sobreexploração. Neste século, se multiplicou por seis a quantidade extraída. A explosão demográfica, a contaminação por errônea utilização, o desperdício e o câmbio climático influenciam diretamente na diminuição dos recursos hídricos.

O Brasil recebe uma abundante pluviometria que varia sobre mais de $90 \%$ do seu território, entre 1.000 e mais de 3.000 mm/ano. Num dos países mais ricos em água doce do planeta, as cidades enfrentam crises de abastecimento, das quais não escapam nem mesmo as localizadas na Região Norte, onde estão perto de $80 \%$ das descargas de água dos rios do Brasil. O país é dotado, também, de uma vasta e densa rede de drenagem que nunca seca sobre mais de $90 \%$ do território nacional, engendrando, certamente, a ideia de abundância de água no Brasil (BARROS e AMIM, 2008).

Por outro lado, os danos ambientais causados pelas atividades humanas podem reduzir a disponibilidade e qualidade dos recursos hídricos. Na agricultura, a FAO estima que cerca de $60 \%$ da água que é fornecida aos projetos de irrigação no mundo se perdem por evaporação ou percolação. Por sua vez, as Nações Unidas (ONU, 2003) estimam que a redução de $10 \%$ da água utilizada na agricultura já seria suficiente para abastecer o dobro da população mundial atual, de 6,3 bilhões de pessoas. No Brasil, a exemplo de outros países, a maior demanda por água é da agricultura, especialmente a irrigação, com quase $63 \%$ de toda a demanda (BARROS e AMIM, 2008).

A ONU estima que mais da metade dos rios do mundo está poluída pelos despejos dos esgotos domésticos, efluentes industriais, agrotóxicos e dejetos de animais. Nos municípios menores, como é o caso do município pesquisado, a maioria dos poços de abastecimento encontra-se na zona rural. Porém, em propriedades rurais os danos ambientais muitas vezes estão relacionados às atividades agrícolas. Dessa forma, a escassez de água adequada ao consumo é uma das grandes problemáticas ambientais enfrentadas pela 
população e o monitoramento das fontes de abastecimento é indispensável à preservação ambiental e a saúde da população (LOBO e CALLEGARO, 2000).

O Brasil possui legislações específicas referentes à qualidade da água. Uma delas é a Resolução do Conselho Nacional do Meio Ambiente (CONAMA) no 357, de 2005 (BRASIL, 2005) que dispõe sobre a classificação e diretrizes ambientais para o enquadramento dos corpos de água superficiais, estabelecendo limites individuais a cada substância a ser analisada.

Dessa forma, o desmatamento e a contaminação dos lençóis freáticos altera de maneira significativa a qualidade da água que é consumida pela população de uma determinada cidade ou localidade. $\mathrm{O}$ consumo de água contaminada por agentes biológicos ou físicoquímicos afeta a saúde da população de forma significativa (SILVA e ARAÚJO, 2003).

$\mathrm{O}$ acesso à água potável, livre de microorganismos patogênicos, de substâncias e elementos químicos prejudiciais à saúde, é direito fundamental de todo cidadão. A Lei 11.445 (BRASIL, 2007), que estabelece diretrizes nacionais para o saneamento básico, tem como fundamento a universalização do acesso aos serviços de saneamento básico entre eles o abastecimento de água potável.

O objetivo deste estudo foi avaliar a qualidade físico-química e microbiológica da água de dez poços de associações da zona rural, localizadas no município de Imigrante, Rio Grande do Sul, realizando um comparativo entre os parâmetros determinados pela Resolução CONAMA n 357 de 17 de março de 2005 (BRASIL, 2005) e Portaria do Ministério da Saúde no 2.914 de 12 de dezembro de 2011 (BRASIL, 2011). A resolução 357/2005, embora aplicada a águas superficiais, foi utilizada como referencial de comparação, pois dá uma noção, a partir da classificação da água da complexidade ou não de seu tratamento para fins de consumo humano.

\section{Material e métodos}

\section{Área de estudo}

O estudo foi conduzido no município de Imigrante/RS, localizado na região geopolítica do Vale do Taquari (Figura 1), no centro-leste do
Estado do Rio Grande do Sul (BDR, 2014). Foram selecionados dez poços de associações comunitárias da zona rural do município (Quadro 1) através de listagem fornecida pela Prefeitura Municipal e com a autorização das diretorias das comunidades de água responsáveis pela gestão desse recurso no Município de Imigrante.

Figura 1: Mapa do município de Imigrante em contexto de estado e região.

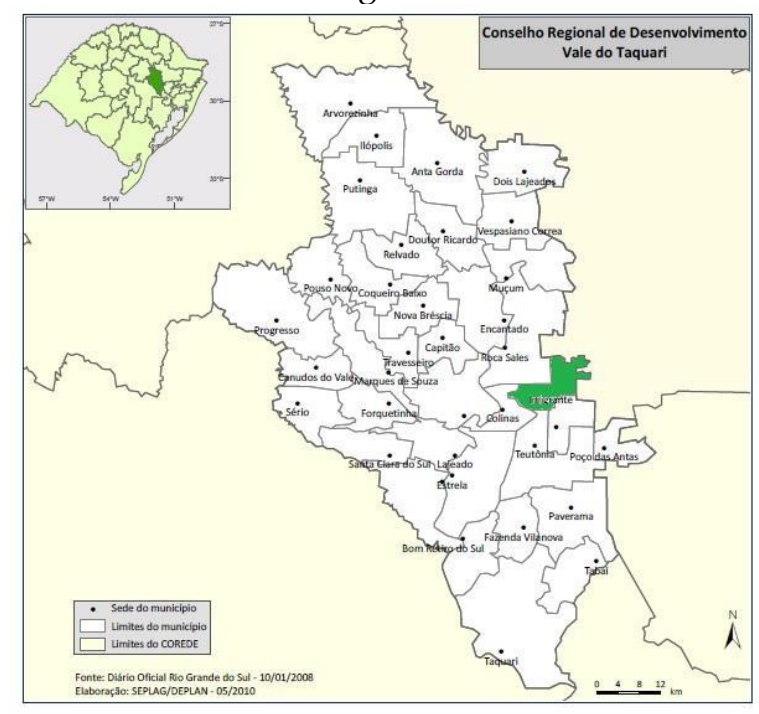

Em Imigrante, existem 16 (dezesseis) poços artesianos profundos e dois barramentos superficiais que são gerenciados por sociedades de água com o apoio da Administração Pública Municipal. Além destes poços, ainda existem poços artesianos particulares. Todos os poços analisados não são clorados. Os poços naturais de onde a água foi coletada abastecem cerca de 486 famílias, em diferentes comunidades da área rural do município.

De acordo com dados da administração municipal (IMIGRANTE, 2014), as principais atividades econômicas do município são a indústria (metalúrgica, produtos de limpeza, cutelaria, confecções, laticínios etc.) e agricultura (com a produção de leite, aves, suínos e outros). Além disso, o setor de serviços também possui um grande impacto no Valor Adicionado Bruto, chegando a contribuir com $37,7 \%$ do total apurado para o ano de 2008 (HEBERLE e ZERBIELLI, 2014). 
Quadro 1: Dados de localização, altitude e coordenadas do poço, número de famílias atendidas, vazão, profundidade da bomba e ano de perfuração.

\begin{tabular}{|c|c|c|c|c|c|c|c|c|c|}
\hline $\begin{array}{l}\text { № do } \\
\text { poço }\end{array}$ & Localidade & Poço & $\begin{array}{c}\text { Coordenadas } \\
\text { geográficas } \\
\text { (DATUM } \\
\text { WGS84) }\end{array}$ & $\begin{array}{l}\text { Altitude } \\
\text { (m) }\end{array}$ & $\begin{array}{l}\text { Proteção } \\
\text { sanitária }\end{array}$ & $\begin{array}{c}\text { Famílias } \\
\text { atendidas }\end{array}$ & $\begin{array}{l}\text { Vazão } \\
\left(\mathrm{m}^{3} / \mathrm{h}\right)\end{array}$ & $\begin{array}{c}\text { Ano de } \\
\text { perfuração } \\
\text { aproximado }\end{array}$ & $\begin{array}{l}\text { Profundidade } \\
\text { da bomba (m) }\end{array}$ \\
\hline 1 & Seca Baixa & $\mathrm{TP}$ & $\begin{array}{c}29^{\circ} 22^{\prime} 5.87^{\prime \prime S} \\
51^{\circ} 49^{\prime} 18.31^{\prime \prime O}\end{array}$ & 60 & ausente & 138 & NS & 1980 & 36 \\
\hline 2 & Seca Baixa & $\mathrm{TP}$ & $\begin{array}{l}29^{\circ} 21^{\prime} 40.42^{\prime \prime S} \\
51^{\circ} 47^{\prime} 30.27^{\prime \prime} \mathrm{O}\end{array}$ & 80 & ausente & 138 & NS & 1980 & 60 \\
\hline 3 & Castro Alves & $\mathrm{TP}$ & $\begin{array}{l}29^{\circ} 21^{\prime} 48.22^{\prime \prime S} \\
51^{\circ} 45^{\prime} 23.36^{\prime \prime O}\end{array}$ & 220 & ausente & 18 & NS & 1990 & 80 \\
\hline 4 & Imhoff & $\mathrm{TP}$ & $\begin{array}{l}29^{\circ} 20^{\prime} 42.85^{\prime \prime S} \\
51^{\circ} 45^{\prime} 41.08^{\prime \prime} \mathrm{O}\end{array}$ & 130 & ausente & 43 & 15 & 1990 & 65 \\
\hline 5 & Boa Vista 37 & $\mathrm{TP}$ & $\begin{array}{l}29^{\circ} 21^{\prime} 15.44^{\prime \prime S} \\
51^{\circ} 44^{\prime} 17.68^{\prime \prime} \mathrm{O}\end{array}$ & 165 & ausente & 26 & 6 & 1997 & NS \\
\hline 6 & Rosenthal & $\mathrm{TP}$ & $\begin{array}{l}29^{\circ} 19^{\prime} 46.48^{\prime \prime S} \\
51^{\circ} 43^{\prime} 39.65^{\prime \prime O}\end{array}$ & 185 & ausente & 33 & 15 & 1990 & 20 \\
\hline 7 & $\begin{array}{c}\text { Vale da } \\
\text { Harmonia }\end{array}$ & $\mathrm{TP}$ & $\begin{array}{l}29^{\circ} 18^{\prime} 24.30^{\prime \prime} \mathrm{S} \\
51^{\circ} 42^{\prime} 28.85^{\prime \prime} \mathrm{O}\end{array}$ & 215 & ausente & 40 & 20 & 1993 & 40 \\
\hline 8 & $\begin{array}{c}\text { Harmonia } \\
\text { Alta }\end{array}$ & $\mathrm{TP}$ & $\begin{array}{c}29^{\circ} 18^{\prime} 4.56^{\prime \prime S} \\
51^{\circ} 43^{\prime} 39.18^{\prime \prime} \mathrm{O}\end{array}$ & 425 & ausente & 17 & 3,5 & 2006 & 120 \\
\hline 9 & Garibaldi & $\mathrm{BCH}$ & $\begin{array}{c}29^{\circ} 18^{\prime} 0.13^{\prime \prime S} \\
51^{\circ} 45^{\prime} 28.14^{\prime \prime} \mathrm{O}\end{array}$ & 530 & precária & 8 & NS & 1990 & superficial \\
\hline 10 & Michels & $\mathrm{TP}$ & $\begin{array}{c}29^{\circ} 20^{\prime} 0.39^{\prime \prime} \mathrm{S} \\
51^{\circ} 45^{\prime} 32.77^{\prime \prime} \mathrm{O}\end{array}$ & 225 & precária & 25 & 5 & 2006 & 30 \\
\hline
\end{tabular}

\section{Coleta e análise de dados}

As coletas foram realizadas no dia 08 de agosto de 2014, no período da tarde, em dez poços de diferentes localidades (Figura 2). No momento de cada coleta foram registrados os dados geográficos, utilizando GPS Garmin Dakota 20.

As amostras de água foram coletadas para análise química em dois recipientes de vidro de $200 \mathrm{~mL}$, devidamente higienizados e identificados. Para as análises microbiológicas, utilizou-se frasco de vidro de $600 \mathrm{~mL}$, esterilizado em autoclave. As coletas foram executadas na residência mais próxima ao poço natural da qual as águas provinham, quando não havia torneira na saída da bomba (Figura 3). Antes da coleta, as torneiras eram flambadas para higienização, posteriormente deixava-se a água escorrer por aproximadamente um minuto para evitar interferências do meio externo nos resultados. Após, a coleta das amostras de água, verificou-se a temperatura da mesma e do ambiente, além de fazer a medida de oxigênio dissolvido, com oxímetro, ainda em campo. As amostras foram acondicionadas em recipiente térmico para posterior análise em laboratório.

No Laboratório de Química da Univates foram realizados o restante das análises. Para cada amostra coletada analisou-se: temperatura, turbidez, colorimetria, $\mathrm{pH}$, condutividade, dureza, fósforo total, carbono orgânico, carbono inorgânico, carbono total, nitrogênio, sólidos totais suspensos e análise microbiológica. Foram também analisados os íons Fluoreto, Cloreto, Nitrato e Sulfato. Cada parâmetro foi analisado em equipamento específico (Quadro 2). 
Figura 2: Mapa da localização dos poços no município. Adaptado de Brasil (1980a; 1980b).

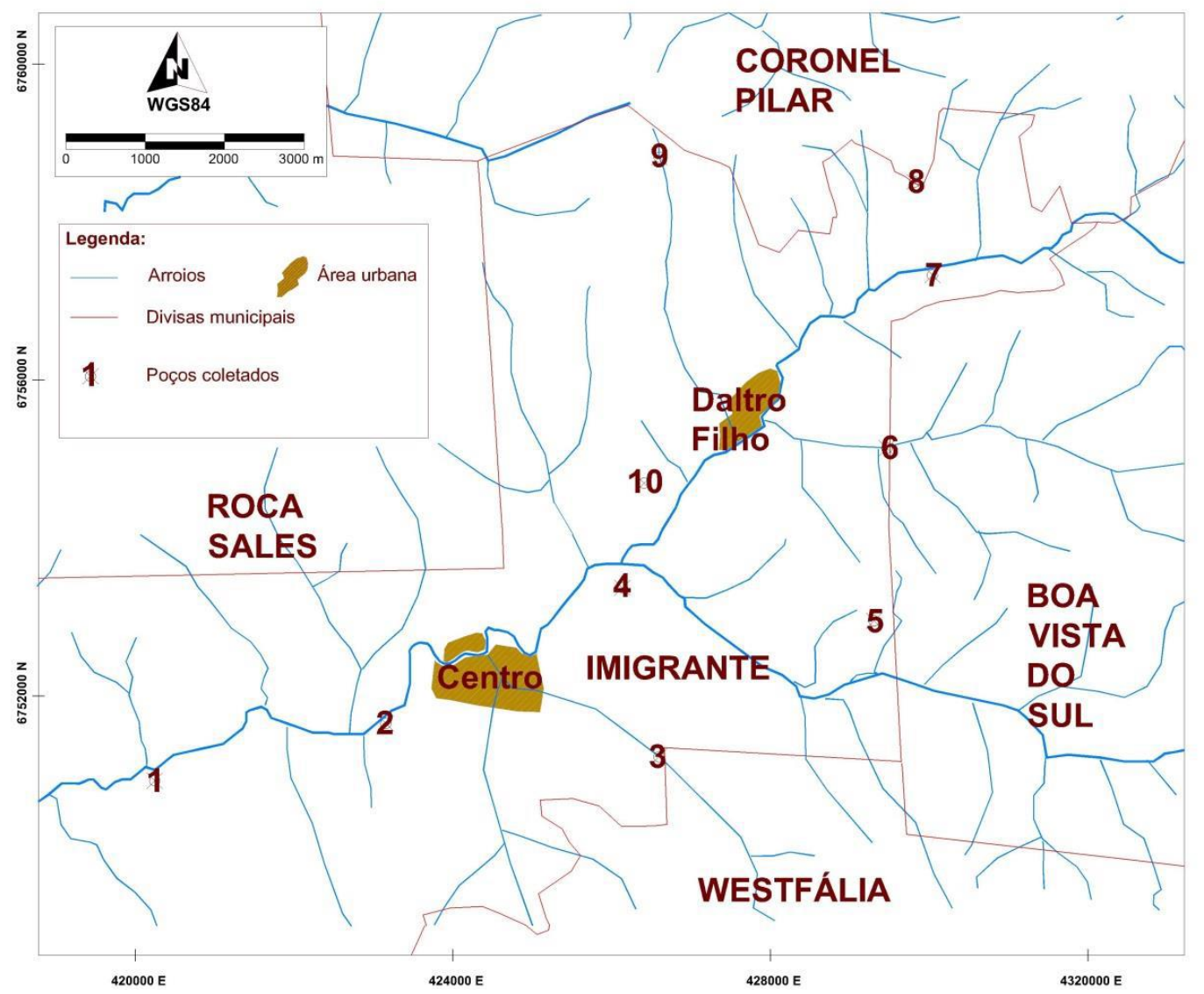

Figura 3: Coleta de água junto à unidade consumidora mais próxima à fonte natural (Poço 2).

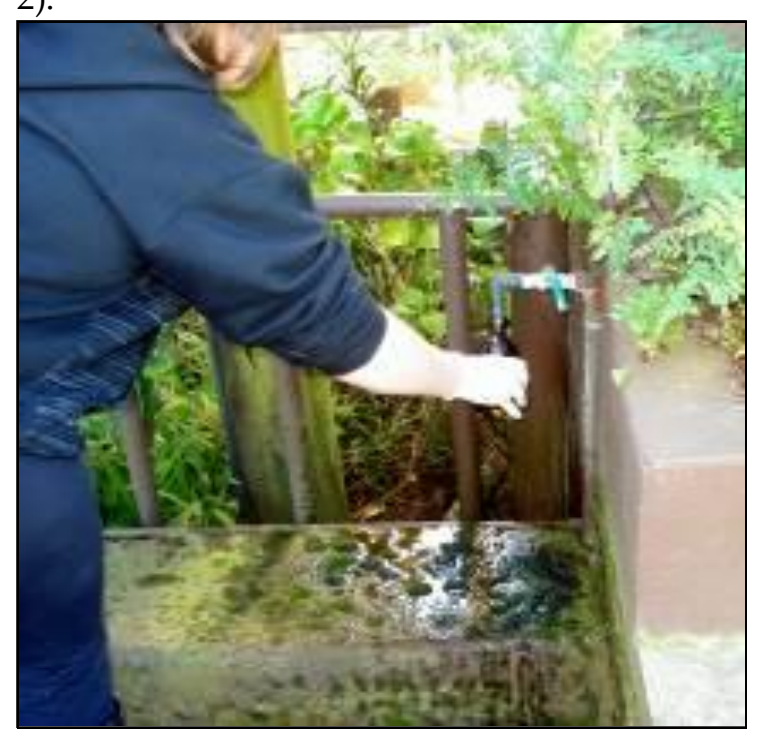

Todos os dados foram tabulados no software Microsoft Excel ${ }^{\circledR}$ 2010. Os dados físicoquímicos da água foram comparados mediante o uso de desvio-padrão obtido no software Microsoft Excel $^{\circledR} \quad 2010$. As análises microbiológicas foram realizadas através do método de tubos múltiplos, usando-se caldo lactosado e laurel, com alíquotas de $100 \mathrm{~mL}$ de amostra, de acordo com descrição de Standard Methods for Water and Wastewater Examination (AMERICAN, 1992).

Para a verificação da potabilidade da água foram comparados os parâmetros obtidos com as definições da Portaria do Ministério da Saúde no 2.914 de 12/12/2011 (BRASIL, 2011). 
Quadro 2: Dados dos equipamentos/técnicas utilizadas para análise de cada parâmetro.

\begin{tabular}{|c|c|c|c|c|}
\hline Parâmetro & Técnica/aparelho & Unidade de medida & Marca & Modelo \\
\hline $\begin{array}{l}\text { Altimetria do poço e } \\
\text { do ponto de coleta }\end{array}$ & $\begin{array}{l}\text { Comparação do GPS } \\
\text { com o Google Earth }\end{array}$ & $\mathrm{m}$ & Garmin / Google & Dakota 20 / Earth \\
\hline $\begin{array}{l}\text { Ano de perfuração do } \\
\text { poço }\end{array}$ & $\begin{array}{c}\text { Entrevista com a } \\
\text { diretoria }\end{array}$ & Ano & - & - \\
\hline Carbono inorgânico & $\begin{array}{c}\text { Carbono orgânico total } \\
\text { (COT) }\end{array}$ & $\mathrm{mg} \cdot \mathrm{L}^{-1}$ & Shimadzu & TOC-V CPH e TNM-1 \\
\hline Carbono orgânico & $\begin{array}{c}\text { Carbono orgânico total } \\
\text { (COT) }\end{array}$ & $\mathrm{mg} \cdot \mathrm{L}^{-1}$ & Shimadzu & TOC-V CPH e TNM-1 \\
\hline Carbono total & $\begin{array}{c}\text { Carbono orgânico total } \\
\text { (COT) }\end{array}$ & $\mathrm{mg} \cdot \mathrm{L}^{-1}$ & Shimadzu & TOC-V CPH e TNM-1 \\
\hline Coliformes totais & $\begin{array}{l}\text { Standard methods } \\
\text { (APHA, 2001) }\end{array}$ & NMP & - & - \\
\hline Colorimetria & Colorímetro & $\mathrm{mgPT}-\mathrm{Co} / \mathrm{L}$ & Digimed & DM-COR \\
\hline Condutividade & Condutivímetro & $\mu \mathrm{S} . \mathrm{cm}^{-1}$ & Digicron Analytical & DM-32 \\
\hline $\begin{array}{l}\text { Coordenadas } \\
\text { geográficas do poço e } \\
\text { do ponto de coleta }\end{array}$ & GPS (DATUM WGS84) & $\begin{array}{l}\text { Graus, minutos, } \\
\text { segundos }\end{array}$ & Garmin & Dakota 20 \\
\hline $\begin{array}{l}\text { Descrição do entorno } \\
\text { do poço }\end{array}$ & Verificação in loco & - & - & - \\
\hline Dureza & $\begin{array}{l}\text { Compleximetria do } \\
\text { EDTA (AMERICAN } \\
\text { WATER WORKS } \\
\text { ASSOCIATION, 1995) }\end{array}$ & $\mathrm{mg} \mathrm{CaCO} 3 . \mathrm{L}^{-1}$ & - & - \\
\hline Famílias atendidas & $\begin{array}{c}\text { Entrevista com a } \\
\text { diretoria }\end{array}$ & - & - & - \\
\hline $\begin{array}{l}\text { Íons em solução } \\
\text { (fluoretos, cloretos, } \\
\text { bromato, brometo, } \\
\text { fósforo, nitrato, nitrito } \\
\text { e sulfato) }\end{array}$ & Cromatografia de íons & $\mathrm{mg} \cdot \mathrm{L}^{-1}$ & Metrohm & Compact IC pro 881 \\
\hline Nitrogênio total & $\begin{array}{c}\text { Carbono orgânico total } \\
\text { (COT) }\end{array}$ & $\mathrm{mg} \cdot \mathrm{L}^{-1}$ & Shimadzu & TOC-V CPH e TNM-1 \\
\hline Nome da localidade & $\begin{array}{l}\text { Entrevista com a } \\
\quad \text { diretoria }\end{array}$ & - & - & - \\
\hline Oxigênio dissolvido & Oxímetro & $\mathrm{mg} \cdot \mathrm{L}^{-1}$ & Digimed & DM-4P \\
\hline $\mathrm{pH}$ & pHmetro & $\mathrm{pH}$ & Digimed & DM-20 \\
\hline $\begin{array}{l}\text { Presença de Escherichia } \\
\text { coli }\end{array}$ & $\begin{array}{l}\text { Standard methods } \\
\text { (APHA, 1999) }\end{array}$ & NMP & - & - \\
\hline $\begin{array}{l}\text { Presença de proteção } \\
\text { sanitária (cercamento) }\end{array}$ & Verificação in loco & - & - & - \\
\hline $\begin{array}{l}\text { Profundidade } \\
\text { bomba }\end{array}$ & $\begin{array}{l}\text { Entrevista com a } \\
\text { diretoria }\end{array}$ & - & - & - \\
\hline Sólidos totais & $\begin{array}{l}\text { Sólidos totais secos a } \\
103-105^{\circ} \mathrm{C} \\
\text { (AMERICAN WATER } \\
\text { WORKS } \\
\text { ASSOCIATION, 1995) }\end{array}$ & $\mathrm{mg}$ & - & - \\
\hline Temperatura & Termômetro químico & ${ }^{\circ} \mathrm{C}$ & - & - \\
\hline
\end{tabular}




\begin{tabular}{|c|c|c|c|c|}
\hline Parâmetro & Técnica/aparelho & Unidade de medida & Marca & Modelo \\
\hline \multicolumn{5}{|l|}{ ambiente } \\
\hline $\begin{array}{l}\text { Tipo de poço (tubular } \\
\text { profundo, escavado ou } \\
\text { barramento de curso } \\
\text { hídrico) }\end{array}$ & Verificação in loco & - & - & - \\
\hline Turbidez & Turbidímetro & NTU & Digimed & DM-TU \\
\hline Vazão & $\begin{array}{c}\text { Entrevista com a } \\
\text { diretoria }\end{array}$ & - & - & - \\
\hline
\end{tabular}

\section{RESULTADOS E DISCUSSÃO}

Os resultados da determinação dos parâmetros físico-químicos e microbiológicos descritos anteriormente são apresentados nas Tabelas 1, 2, 3 e 4 .

Tabela 1: Resultados dos parâmetros: Média de Oxigênio Dissolvido - OD, Temperaturas da água e do ambiente, $\mathrm{pH}$, condutividade, turbidez, colorimetria, dureza e sólidos totais, para os dez pontos de coleta nos poços das Sociedades de água analisadas, em Imigrante, RS.

\begin{tabular}{|c|c|c|c|c|c|c|c|c|c|}
\hline Amostra & $\begin{array}{c}\text { OD } \\
\text { (mg.L-1) }\end{array}$ & $\begin{array}{c}\text { Temp. } \\
\text { ambiente } \\
\left({ }^{\circ} \mathrm{C}\right)\end{array}$ & $\begin{array}{c}\text { Temp. } \\
\text { amostra } \\
\left({ }^{\circ} \mathrm{C}\right)\end{array}$ & $\mathrm{pH}$ & $\begin{array}{c}\text { Condutividade } \\
(\mu \mathrm{S} / \mathrm{cm})\end{array}$ & $\begin{array}{c}\text { Turbidez } \\
\text { (NTU) }\end{array}$ & $\begin{array}{l}\text { Colorimetria } \\
(\mathrm{mg} \text { Pt-Co.L-1) }\end{array}$ & $\begin{array}{c}\text { Dureza } \\
\left(\mathrm{mg} \mathrm{CaCO}_{3} \cdot \mathrm{L}^{-1}\right)\end{array}$ & $\begin{array}{c}\text { Sólidos } \\
\text { Totais } \\
\left(\mathrm{mg.L}^{-1}\right)\end{array}$ \\
\hline 2 & 6,7 & 18 & 15,3 & 7,9 & 305,7 & 0,92 & 1,3 & 82,8 & 85 \\
\hline 3 & 7,5 & 16 & 17 & 7,4 & 278,6 & 0,06 & 1,0 & 132 & 80 \\
\hline 5 & 7,5 & 13,5 & 16 & 7,9 & 294,2 & 0,03 & nd & 73,4 & 155 \\
\hline 6 & 7,1 & 14 & 17,2 & 7,6 & 316 & 0,41 & 1,1 & 154,2 & 125 \\
\hline 7 & 6,1 & 12,5 & 17 & 7,6 & 280,8 & 1,32 & nd & 130,6 & 65 \\
\hline
\end{tabular}

nd: não detectado

Não houve variação significativa da temperatura entre as amostras (Tabela 1), com isso, os resultados também não variaram significativamente em razão deste parâmetro (ANA, 2009).

A medida de oxigênio dissolvido foi efetuada no momento da coleta da água, e de acordo com a legislação em vigência no Brasil (BRASIL, 2005; 2011), as amostras de água doce, para serem classificadas como em Classe 1 de potabilidade não podem ter oxigênio dissolvido inferior a $6 \mathrm{mg} \cdot \mathrm{L}^{-1}$. Para a classificação como Classes 2 e 3, os níveis de oxigênio dissolvido não devem ser inferiores a
$5 \mathrm{mg} . \mathrm{L}^{-1}$ e $4 \mathrm{mg} . \mathrm{L}^{-1}$, respectivamente. Todas as amostras dos poços naturais do município de Imigrante/RS, com exceção do Poço 8, podem ser classificadas como Classe 1 , segundo o parâmetro oxigênio dissolvido (Tabela 1).

O baixo nível de oxigênio dissolvido, conforme Janzen et al. (2008) indica consumo de oxigênio por decomposição da matéria orgânica ou respiração realizada por microorganismos. Porém, conforme se pode observar na Tabela 2, o carbono orgânico do Poço 8 não varia significativamente dos demais poços. 
De acordo com os padrões de classificação e de potabilidade da água, respectivamente, da Resolução CONAMA 357/2005 (BRASIL, 2005) e pela Portaria do Ministério da Saúde no 2.914/2011 (BRASIL, 2011) é recomendado que o $\mathrm{pH}$ da água no sistema de distribuição esteja entre 6,0 e 9,5. Em todas as amostras analisadas, o $\mathrm{pH}$ ficou entre os índices recomendados pela legislação brasileira, não havendo uma diferença significativa entre os valores encontrados nos diferentes pontos de coleta (Tabela 1).

A média de $\mathrm{pH}$ das amostras do estudo é de 7,65 $( \pm 0,25)$, não sendo significativamente diferente em comparação à média de 6,86 $( \pm 0,66)$ em Lajeado/RS (ECKHARDT et al., 2009).

Quanto ao parâmetro turbidez, a Resolução CONAMA 357/2005 (BRASIL, 2005) dispõe que os limites máximos para classificação das águas doces em Classe 1 não podem ser superiores a 40 UT, já a Portaria do Ministério da Saúde no 2.914/2011 (BRASIL, 2011), publicada posteriormente, prevê que os valores não podem ultrapassar 5,0 UT para águas subterrâneas com desinfecção. Como nos poços objetos desse estudo não é feito nenhum tipo de desinfecção, nem mesmo cloração, os índices dos poços que se encontram em desacordo (Poços 8 e 9 ) poderiam melhorar se fosse realizado algum tipo de tratamento antes do consumo dessa água pelas famílias abastecidas por essas comunidades. A determinação de turbidez da água é diretamente influenciada pela presença de material sólido em suspensão, o que afeta a transparência da mesma. Além disso, Correia et al. (2008) sugerem, para reduzir os níveis de turbidez, adotar os procedimentos sequenciais de coagulação, floculação, sedimentação e filtração.

Quanto maior a quantidade de sólidos dispersos no corpo hídrico, maiores os valores dos parâmetros turbidez, colorimetria e sólidos totais (TEIXEIRA e SENHORELO, 2000).

Como pode ser observado na Tabela 1 , os poços que possuem valores de turbidez mais elevados também possuem maiores valores no campo colorimetria, e a quantidade de sólidos totais do corpo hídrico está relacionada não só com esses índices, como também com os índices de dureza da água. Nessa análise, pode ser observado que no Poço 8, que possui valores mais elevados de turbidez e colorimetria, os níveis de dureza também são elevados. Dessa forma, o valor dos sólidos totais nessa amostra foi muito diferente do encontrado nos outros mananciais.

Já o poço 9, que é o único do tipo barramento superficial, mesmo apresentando valores de turbidez e colorimetria diferentes dos demais poços, apresenta os menores índices de dureza, podendo-se observar, que os valores de sólidos totais foram nulos. A ausência de sólidos totais relaciona-se, também, ao baixo valor de condutividade do Poço 9, pois, conforme Dias e Lima (2004), os sólidos são geralmente sais dissolvidos, os quais transformam a água num eletrólito capaz de conduzir a corrente elétrica. Por outro lado, o Poço 8, apesar de possuir alto valor de sólidos totais, não varia significativamente dos demais no parâmetro de condutividade. Isto se deve provavelmente à presença de sólidos não iônicos em maior concentração (SAMPAIO et al., 2007).

A Portaria do Ministério da Saúde $\mathrm{n}^{\mathrm{o}}$ 2.914/2011 (BRASIL, 2011), prevê que os índices máximos para colorimetria (cor

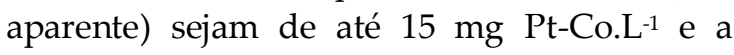
dureza expressa em carbonato de cálcio e calculada como a soma das concentrações de íons cálcio e magnésio na água, não podem ser superiores

$500 \mathrm{mg} \cdot \mathrm{L}^{-1}$. Nesse sentido, apenas o poço 8 não está dentro dos padrões estabelecidos pela portaria, visto que apresenta índice colorimétrico acima do permitido. Quanto à dureza, todos os poços estão em concordância com a legislação vigente acordo.

A média das durezas do presente estudo em Imigrante é de $121,13 \pm 43,88 \mathrm{mg} \cdot \mathrm{L}^{-1}$, não diferindo significativamente das águas de poços rasos e profundos de Lajeado/RS com média de $84,79 \pm 45,26 \mathrm{mg} . \mathrm{L}^{-1}$ (ECKHARDT et al., 2009).

De acordo com Parron et al., (2011, p. 18), o Carbono Orgânico Total (COT) é um ótimo indicador de qualidade de água, visto que é obtido através da oxidação do carbono, 
servindo como "medida direta da diversidade de compostos orgânicos em vários estados de oxidação em uma amostra de água". Dessa forma, quanto menores os índices, melhor a qualidade da água.

Os valores expressos na Tabela 2 demonstram os valores de Carbono orgânico, Carbono inorgânico, Carbono Total e Nitrogênio total, no entanto não se observou diferença significativa entre as amostras. Os valores mais elevados de Carbono inorgânico presentes nos poços $6,7,8$ e 10 podem estar relacionados à maior turbidez.

Libânio et al. (2000) menciona que apesar de não haver parâmetros legais para $o$ limite de carbono orgânico, a equipe conclui pela utilização do valor máximo de $3 \mathrm{mg} . \mathrm{L}^{-1}$, pois dentro deste universo, existem diversas substâncias tóxicas, principalmente agrotóxicos, estando as amostras do presente estudo dentro do limite estipulado (Tabela 2).

O parâmetro de nitrogênio total também não varia significativamente de Lajeado/RS, onde foram constatados poços com valores acima de 0 para tal parâmetro, sendo a média de $2,53 \pm 2,77$ mg. L $^{-1}$ (ECKHARDT et al., 2009).

Tabela 2: Resultados das análises de Carbono Orgânico, Carbono Inorgânico, Carbono Total e Nitrogênio para os dez pontos de coleta nos poços das Sociedades de água analisadas, em Imigrante, RS.

\begin{tabular}{c|cccc}
\hline \multirow{2}{*}{ Amostra } & \multicolumn{4}{|c}{ Concentração $\left(\mathbf{m g . \mathbf { L } ^ { - 1 } \text { ) }}\right.$} \\
\cline { 2 - 5 } & $\begin{array}{c}\text { Carbono } \\
\text { Orgânico }\end{array}$ & $\begin{array}{c}\text { Carbono } \\
\text { Inorgânico }\end{array}$ & $\begin{array}{c}\text { Carbono } \\
\text { total }\end{array}$ & $\begin{array}{c}\text { Nitrogênio } \\
\text { total }\end{array}$ \\
\hline 1 & 1,519 & 39,55 & 41,069 & nd \\
2 & 1,397 & 37,63 & 39,027 & nd \\
3 & 1,474 & 38,33 & 39,804 & nd \\
4 & 1,47 & 32,86 & 34,33 & nd \\
5 & 1,359 & 30,48 & 31,839 & nd \\
6 & 1,768 & 60,66 & 62,428 & nd \\
7 & 1,745 & 92,26 & 94,005 & nd \\
8 & 1,621 & 76,38 & 78,001 & nd \\
9 & 1,802 & 1,945 & 3,747 & nd \\
10 & 1,121 & 75,22 & 76,341 & nd \\
\hline
\end{tabular}

nd: não detectado

Em relação às análises de íons, todos os poços se encontram em concordância com o estipulado pela legislação brasileira para os seguintes parâmetros: fluoreto, cloreto, brometo e sulfato (Tabela 3). A análise de nitratos mostrou que dos dez poços naturais analisados, quatro estavam em desacordo com as normas brasileiras (Poços, 4, 5, 6 e 9), e o que chamou mais a atenção, é que o poço 6 estava mais de quatro vezes acima do limite estipulado pela Portaria 2.914/2011 (BRASIL, 2005; 2011). Segundo esta portaria, o padrão de potabilidade para este tipo de substância química é de no máximo $10 \mathrm{mg} . \mathrm{L}^{-1}$.

Tabela 3: Resultados das análises dos íons fluoreto, cloreto, brometo, bromato, nitrito, nitrato e sulfato para os dez pontos de coleta nos poços das Sociedades de água analisadas, em Imigrante, RS.

\begin{tabular}{c|ccccc}
\hline \multirow{2}{*}{ Poço } & \multicolumn{5}{c}{ Concentração $\left(\mathbf{m g} \cdot \mathbf{L}^{-1}\right)$} \\
\cline { 2 - 6 } & Fluoreto & Cloreto & Brometo & Nitrato & Sulfato \\
\hline 1 & 0,124 & 4,417 & 0,15 & 6,366 & 2,978 \\
2 & 0,205 & 2,12 & nd & 1,181 & 2,018 \\
3 & 0,16 & 3,255 & 0,16 & 4,11 & 2,347 \\
4 & 0,247 & 4,851 & 0,149 & 10,565 & 19,336 \\
5 & 0,169 & 5,02 & nd & 28,132 & 2,889 \\
6 & 0,154 & 5,437 & 0,148 & 41,634 & 6,432 \\
7 & 0,188 & 4,928 & 0,176 & 9,265 & 3,986 \\
8 & 0,223 & 6,485 & 0,182 & 1,208 & 10,571 \\
9 & 0,082 & 4,474 & nd & 24,851 & 1,688 \\
10 & 0,15 & 3,57 & 0,146 & 5,208 & 3,306 \\
\hline
\end{tabular}

nd= não detectado

Os íons bromato e nitrito não foram detectados nas dez amostras estudadas. O nitrato ocorre normalmente na composição do solo e da água, porém a sua concentração junto às águas subterrâneas pode ser alterada pelo uso intensivo de fertilizantes utilizados na agricultura e pela incorreta disposição dos resíduos de esgoto doméstico (ROSSI et al., 2007). No entorno do poço 06, há pastagens para criação de gado, galpões e residências, o que pode ter gerado a contaminação da água por esses íons.

Os poços 4 e 5 tem no seu entorno lavouras, e a sua contaminação por nitrato pode ter sido causada por fertilizantes amplamente utilizados na agricultura. Além disso, pode ser causada também pela 
utilização de fezes de animais como forma de adubação das culturas plantadas nesses locais.

A maioria dos poços não apresentou contaminação por coliformes totais nem por Escherichia coli. Os poços 4 e 9 apresentaram resultado positivo para a presença de coliformes totais e E. coli. O poço 8 somente apresentou resultado positivo para coliformes totais (Tabela 4). Esses resultados demonstram que os poços apresentam contaminação por fezes.

Tabela 4: Resultados da análise microbiológica para os parâmetros Coliformes Totais e Escherichia coli, para os dez pontos de coleta nos poços das Sociedades de água analisadas, em Imigrante, RS.

\begin{tabular}{ccc}
\hline Amostra & $\begin{array}{c}\text { Coliformes Totais } \\
\text { (NMP) }\end{array}$ & $\begin{array}{c}\text { Escherichia coli } \\
\text { (NMP) }\end{array}$ \\
\hline 1 & nd & nd \\
2 & nd & nd \\
3 & nd & nd \\
4 & 9,2 & 9,2 \\
5 & nd & nd \\
6 & nd & nd \\
7 & nd & nd \\
8 & 3,6 & nd \\
9 & 9,2 & 3,6 \\
10 & nd & nd \\
\hline
\end{tabular}

nd: não detectado.

A Portaria 2914 de 2011 do Ministério da Saúde (BRASIL, 2005; 2011) prevê que deve ocorrer ausência tanto de coliformes totais quanto de E. coli em $100 \mathrm{~mL}$ de água. Como o poço 4 apresenta no seu entorno lavouras, pode-se inferir que a contaminação por coliformes e E. coli tenha ocorrido com a utilização de fertilizante orgânico (fezes de suínos ou gado, cama aviária). Já o poço 9, que é o único do tipo barramento superficial analisado, a contaminação pode ter se originado a partir das fezes de animais, visto que está localizado junto a uma pastagem, onde os animais (gado) ficam soltos e além disso, também consomem a água deste recurso. Apesar de haver remanescentes florestais próximos a esse poço, também cabe salientar que os animais utilizam esse local como abrigo em dias de calor, o que também contribui para que seus dejetos entrem em contato com essa água em dias de chuva. $\mathrm{O}$ poço 8 , que apresenta apenas contaminação por coliformes, está localizado junto a um pomar, próximo a residências. Isso pode justificar a contaminação por esse tipo de micro-organismos.

Todos os poços que apresentaram contaminação tanto por coliformes quanto por E. coli devem ser desinfetados, utilizando-se para tal o método de cloração. Além desses, os demais poços, objetos desse estudo, devem passar por verificação periódica, conforme preconiza a legislação vigente, bem com ser clorados, e ter seu $\mathrm{pH}$ corrigido quando necessário.

\section{CONCLUSÃO}

Dentre todos os poços analisados, somente os Poços 1, 2, 3 e 7 não apresentaram nenhum problema ou tiveram algum parâmetro analisado em desacordo com a legislação brasileira, sendo assim, podem ser classificados de acordo a legislação vigente como Água Doce Classe 1. Essa água poderá ser consumida mediante tratamento simplificado, com a utilização de filtro clarificador, desinfecção (uso de cloro) e correção de $\mathrm{pH}$, quando necessário.

O Poço 8 foi o que apresentou a maior quantidade de parâmetros em desacordo com as normas brasileiras. $\mathrm{O}$ poço apresenta altos índices de turbidez, colorimetria e sólidos totais, além de contaminação por Coliformes totais.

O Poço 9 é a única fonte natural analisada do tipo barramento superficial. Talvez em função do tipo e localização do manancial (está localizado junto a uma criação de gado leiteiro, sujeito à pisoteio e contaminação por fezes e urina dos animais) os níveis de turbidez e de nitratos foram elevados.

Outras fontes também tiveram contaminação por nitratos, caso dos Poços 4, 5 e 6. No caso do poço 6 o grau de contaminação foi superior aos demais, visto que o nível de nitrato na água deste poço artesiano foi maior 
que 4 vezes o limite estabelecido pela Portaria $2.914 / 2011$.

Os valores de Coliformes Totais e Escherichia coli nos poços 4 e 10 preocupam, uma vez que esses poços são tubulares profundos, e isso demonstra que está havendo contaminação das águas subterrâneas por fezes. Dessa forma, a não utilização de métodos de desinfecção das águas consumidas pode acarretar graves problemas de saúde à população que se utiliza dessas águas para consumo.

Nenhuma das fontes analisadas recebe tratamento ou desinfecção com acréscimo de cloro antes do consumo, o que pode ser confirmado pelos valores baixos de cloreto das amostras. No entanto, conforme a informação dos presidentes das associações, a partir deste ano, a administração municipal estará exigindo que estas construam e instalem sistema simplificado de tratamento da água e isolamento sanitário para todos os poços que abastecem a população do município, atendendo a legislação federal.

\section{Declaração de Direito Autoral}

Declaramos que o presente artigo é original e não foi submetido à publicação em qualquer outro periódico nacional ou internacional, quer seja em parte ou na íntegra. Declaramos ainda, que após publicado pela Ciência e Natura, ele jamais será submetido a outro periódico. Também temos ciência que a submissão dos originais à Ciência e Natura implica transferência dos direitos autorais da publicação digital e impressa e, a não observância desse compromisso, submeterá o infrator a sanções e penas previstas na Lei de Proteção de Direitos Autorais (nº610, de 19/02/98).

\section{Política de Privacidade}

Os nomes e endereços informados nesta revista serão usados exclusivamente para os serviços prestados por esta publicação, não sendo disponibilizados para outras finalidades ou à terceiros.

\section{Agradecimentos}

Agradecimentos a revisores, colaboradores e agências de fomento (Capes, CNPq, UNIVATES).

\section{Referências}

Almeira, M. (2010). Geografia Global 2. São Paulo: Escala Educacional.

ANA - Agência Nacional de Águas. Indicadores de qualidade: índice de qualidade das águas. 2009. Disponível em: $<$ http://pnqa.ana.gov.br/IndicadoresQA/Ind iceQA.aspx>. Acesso em: 3 set. 2014.

APHA - American Public Health Association. (2001). Compendium of Methods for the Microbiological Examination of foods. $4^{\text {a }}$ Ed. Washington, DC,

Barros, F. G. N.; Amin, M.(2008). Água: um bem econômico de valor para o Brasil e o mundo. Revista Brasileira de Gestão e Desenvolvimento Regional, Taubaté, v. 4, n. 1, p. 75-108. Disponível em: $<$ http://www.rbgdr.net/revista/index.php/r bgdr/article/view/116/106>. Acesso em: 1 set. 2014 .

Benedetti, S. (2012). Avaliação do teor de carbono orgânico total na qualidade da água: aplicação na radiofarmácia. $104 \mathrm{f}$. Dissertação (Mestrado) - Curso de Pósgraduação em Tecnologia Nuclear Aplicações, Departamento de Autarquia Associada à Universidade de São Paulo, Instituto de Pesquisas Energéticas e Nucleares, São Paulo, 2012. Disponível em: <file://C:/Users/cristianzerwes/Downloads/ 2012BenedettiAvaliacao (2).pdf $>$. Acesso em: 03 set. 2014.

Bertoldi, M. R. Hidroguerras: o líquido cobiçado deixa de ser o petróleo. (2001). Jus Navigandi, Teresina, v. 49, n. 5, p.1-1. Disponível em: $<$ http://jus.com.br/artigos/1701/hidroguerra 
s-o-liquido-cobicado-deixa-de-ser-opetroleo>. Acesso em: 01 set. 2014.

Brasil. CONAMA. (2005). Resolução no 357, de 17 de março de 2005. Dispõe sobre a classificação dos corpos de água e diretrizes ambientais para o seu enquadramento, bem como estabelece as condições e padrões de lançamento de efluentes, e dá outras providências. Brasília, 2011. Disponível em: <http://www.mma.gov.br/port/conama/res/ res05/res35705.pdf>. Acesso em: 01 set. 2014.

Brasil. Ministério da Saúde. (2011). Portaria no 2.914, de 12 de dezembro de 2011. Dispõe sobre os procedimentos de controle e de vigilância da qualidade da água para consumo humano e seu padrão de potabilidade. Brasília. Disponível em: $<$ http://bvsms.saude.gov.br/bvs/saudelegis/ gm/2011/prt2914_12_12_2011.html>. Acesso em: 01 set. 2014.

Brasil. Lei no 11.445, de 05 de janeiro de 2007 . Estabelece diretrizes nacionais para $\mathrm{O}$ saneamento básico. Disponível em: $<$ http://www.planalto.gov.br/ccivil_03/_ato 2007-2010/2007/lei/111445.htm>. Acesso em: 01 set. 2014.

Brasil. Ministério do Exército. (1980a). Garibaldi: Folha SH.22-V-D-II-4 MI 2952/4. Rio de Janeiro: Diretoria de Serviço Geográfico, 1980a.

Brasil. Ministério do Exército. (1980b). Lajeado: Folha SH.22-V-D-II-3 MI 2952/3. Rio de Janeiro: Diretoria de Serviço Geográfico.

Correia, A., Barros, E., Silva, J., Ramalho, J. (2008). Análise da turbidez da água em diferentes estados de tratamento. In: VIII ERMAC $8^{\circ}$ ENCONTRO REGIONAL DE MATEMÁTICA APLICADA E COMPUTACIONAL， 8， 2008， Natal. Resumo das comunicações dos minicursos e do minisimpósio. São Carlos: SBMAC Sociedade Brasileira de Matemática Aplicada e Computacional, p. 1 - 5. Disponível

em:
$<$ http://www.dimap.ufrn.br/ sbmac/ermac2 008/Anais/Resumos Estendidos/Analise da turbidez_Aislan Correia.pdf $>$. Acesso em: 2 set. 2014.

Dias, J. C., Lima, W. N. de. (2004). Comparação de métodos para a determinação de matéria orgânica em amostras ambientais. Revista Científica da UFPA, Belém, v. 4, p.1-16. Disponível em: $<$ http://www2.ufpa.br/rcientifica/ed_anterio res/pdf/ed_04_jcd.pdf $>$. Acesso em: 3 set. 2014.

Eckhardt, , R. R. Diedrich, V. L. FerreiraE, E. R., Strohshoen, E.; Demaman, L. C. (2009). Mapeamento e avaliação da potabilidade da água subterrânea do município de Lajeado, RS, Brasil. Ambiente \& Água: An Interdisciplinary Journal of Applied Science, Taubaté, v. 4, n. 1, p. 5880.isponível em: <www.ambiagua.net/seer/index.php/ambiagua/article/download/186/576>.

Acesso em: 3 set. 2014 .

Heberle, D. R., Zervielli, C. J. (Org.). (2011). Perfil socioeconômico do Vale do Taquari. Lajeado: FUVATES, UNIVATES, BDR Banco de Dados Regional, 2011. 38 p. Disponível em: $<$ https://www.univates.br/media/bdr/Perfil _VT_Setembro_2011.pdf $>$. Acesso em: 1 set. 2014.

Janzen, J. G. Schultz, H. E., Lamon, A. W. (2008) Medidas da concentração de oxigênio dissolvido na superfície da água. Engenharia Sanitária e Ambiental, Rio de Janeiro, v. 13, n. 3, p.278-283. Disponível em:

$<$ http://www.scielo.br/pdf/esa/v13n3/a06v1 3n3.pdf >. Acesso em: 2 set. 2014.

Libânio, M., Libânio, P. A. C., Costa, B. M. P., Sperling, E. von. (2000). Avaliação da relevância do carbono orgânico total como parâmetro de caracterização de águas de abastecimento. RBRH - Revista Brasileira de Recursos Hídricos, Porto Alegre, v. 5, n. 4, p.41-55. Disponível em: 
<https://www.abrh.org.br/sgcv3/UserFiles/ Sumarios/7a75612bcba115e2f491cbe541423f dd_7e95c3780d8b671515a1dee23228ea94.pd f>. Acesso em: 3 set. 2014.

Lobo, E. A., Callegaro, V. L. (2000). Avaliação da qualidade de águas doces continentais com base em algas diatomáceas epilíticas: enfoque metodológico. In: TUCCI, C. E. M.; MARQUES, D. M. (Org.). Avaliação e Controle da Drenagem Urbana. Porto Alegre: Ed. Universidade/UFRGS, p. 277300.

Parron, L. M.; Muniz, D. H. de F.; Pereira, C. M. (2011). Documentos 232: Manual de procedimentos de amostragem e análise físico-química de água. Colombo: Embrapa Florestas, 67 p. Disponível em: $<$ http://ainfo.cnptia.embrapa.br/digital/bitst ream/item/57612/1/Doc232ultimaversao.pdf $>$. Acesso em: 1 set. 2014.

Rio Grande do Sul. Secretaria do Planejamento, Gestão e Participação Cidadã. (2008). Conselho Regional de Desenvolvimento Vale do Taquari. 2008. Elaboração: SEPLAG/DEPLAN - 05/2010. Disponível em: $<$ http://www.scp.rs.gov.br/upload/MAPAS _A4_ValeTaquari.pdf $>$. Acesso em: 14 set. 2014.

Rossi, P., Miranda, J. H., Duarte, S. N. (2007). Curvas de distribuição de efluentes do íon nitrato em amostras de solo deformadas e indeformadas. Engenharia Agrícola, Jaboticabal, v. 27, n. 3, p.675-682, 2007. Disponível em:

$<$ http://www.scielo.br/pdf/eagri/v27n3/a10v27 n3.pdf>. Acesso em: 1 set. 2014.

Rutkowski, E. W.., Lessa, S. N., Oliveira, E. G. de. (1999). Desenvolvimento Brasileiro $x$ Meio Ambiente: trajetória da problematização da água. Revista de Ciência \& Tecnologia, Piracicaba: Unimep, v. 7, n. 14, p. 23-30. 1999.

Sampaio, S. C., Silvestro, M. G., Frigo, E. P., Borges, C. M. (2007). Relação entre série de sólidos e condutividade elétrica em diferentes águas residuárias. Irriga, Botucatu, v. 12, n. 4, p.557-562, 2007. Disponível em: <file://C:/Users/cristianzerwes/Downloads/ RI-2007-264.pdf>. Acesso em: 3 set. 2014.

Teixeira, E. C., Senhorelo, A. P. (2000). Avaliação de correlação entre turbidez e concentração de sólidos suspensos em bacias hidrográficas com uso e ocupação diferenciada. Em: XXVII Congresso Interamericano de Engenharia Sanitária e Ambiental 27. Porto Alegre. Anais... São Paulo: AIDIS - Associação Interamericana de Engenharia Sanitária, 2000. p. 1 - 5. Disponível em: $<$ http://www.bvsde.paho.org/bvsaidis/calia gua/v-013.pdf $>$. Acesso em: 1 set. 2014. 